\title{
THE USE OF MULTIPLE TOOLS FOR TEACHING MEDICAL BIOCHEMISTRY
}

\author{
Sé, A.B. ${ }^{1,2}$, Passos R.M. ${ }^{1,2}$, Rochadel, A.D. ${ }^{2}$, Ono, A.H. ${ }^{2}$, Hermes-Lima, M. ${ }^{1}$ \\ ${ }^{1}$ Oxyradical Research Group, CEL, UnB. ${ }^{2} \mathrm{FM}-U n \mathrm{~B}$, Brasília, Brazil.
}

The pros and cons of Problem Based Learning (PBL) have been extensively discussed in the literature. We describe PBL-like strategies used at UnB (some of them since 1999) that may be useful elsewhere to improve undergraduate biochemistry teaching with clinical applications. The main activities are: (i) a seminar/poster system, (ii) a true-or-false applied biochemistry exam (prepared by peer tutors), (iii) a 9-hour-exam on metabolism (based in actual papers), (iv) an Advanced Biochemistry course (directed to peer tutors), (v) pizza-and-pasta (for metabolism teaching) and free radicals (real science for students) experiments, (vi) the BioBio blog (http://www.biobio-unb.blogspot.com), (vii) student lectures on health issues directed to the community, and (viii) the BioBio Show. The main objective of these activities is providing students with a more practical and entertaining approach to biochemistry using philosophic PBL principles such as the application of basic knowledge to real situations (diseases, experiments and scientific discoveries). We also emphasize (a) the importance of peer-tutor activity for optimized learning of students and peer tutors, (b) the relevance of a closer interaction between students and professors, and (c) the necessity to initiate students precociously in actual basic/medical science and contact with the public. Most activities have been evaluated by the students through written questionnaires and informal conversations, for several semesters, indicating good acceptance and approval of these methods. Acknowledgment: Milênio-Redoxoma-CNPq. Keywords: Teaching ; Learning; PBL. 